\title{
Cultivation of Gelidiella acerosa in the open sea on the southeastern coast of India
}

\author{
M. Ganesan ${ }^{1, *}$, S. Thiruppathi ${ }^{1}$, K. Eswaran ${ }^{1}$, C. R. K. Reddy ${ }^{2}$, B. Jha ${ }^{2}$ \\ ${ }^{1}$ Marine Algal Research Station, Central Salt and Marine Chemicals Research Institute, Council of Scientific and Industrial \\ Research, Mandapam Camp - 623 519, Tamilnadu, India \\ ${ }^{2}$ Discipline of Marine Biotechnology \& Ecology, Central Salt and Marine Chemicals Research Institute, Council of Scientific \\ and Industrial Research, Bhavnagar - 364 002, Gujarat, India
}

\begin{abstract}
Four cultivation methods: raft, bottom net, coral block and cement block were evaluated for the propagation of Gelidiella acerosa in the open sea. Of the 4 methods, the raft method resulted in significantly $(\mathrm{p}<0.001$ ) highest daily growth rate (DGR) of 1.11 to $1.31 \%$ and biomass of 973 to $1288 \mathrm{~g}$ fresh weight (wt) $\mathrm{m}^{-2}$. Biomass values showed direct correlation with initial seedling densities. Initial seedling densities $\geq 500 \mathrm{~g}$ fresh $\mathrm{wt} \mathrm{m}^{-2}$ registered maximum yields of $1425 \pm 90 \mathrm{~g}$ fresh wt $\mathrm{m}^{-2}$, while lower initial seedling density $\left(200 \mathrm{~g}\right.$ fresh wt $\left.\mathrm{m}^{-2}\right)$ showed higher DGR values $(0.71 \pm 0.07$ and $0.48 \pm 0.06 \%$ during the 1 st and 2 nd harvests respectively). The $180 \mathrm{~d}$ cultivation period registered the highest yield of $367 \pm 45 \mathrm{~g}$ fresh wt $\mathrm{m}^{-2}$, which significantly differed $(\mathrm{p}<0.001)$ from values obtained for the 30,60 and 90 d cultivation periods. The germplasm collected from Sethukarai (subtidal reef) showed the highest yield $\left(525 \pm 34.6 \mathrm{~g}\right.$ fresh $\left.\mathrm{wt} \mathrm{m}^{-2}, \mathrm{p}<0.001\right)$ and DGR $(0.54 \pm 0.04 \%)$ compared with those collected from Pudumadam (intertidal rock), Ervadi (intertidal reef) and Rameswaram (subtidal rock). The findings of this study indicate that the raft method of cultivation using germplasm from Sethukarai, an initial seedling density of $\geq 500 \mathrm{~g}$ fresh wt $\mathrm{m}^{-2}$ and a $180 \mathrm{~d}$ cultivation period are important criteria for the successful cultivation of G. acerosa. The augmentation of exploited seaweeds through cultivation practices will help preserve natural biodiversity and ecosystem functioning.
\end{abstract}

KEY WORDS: Bamboo raft · Coral block · Daily growth rate $\cdot$ Gelidiella acerosa $\cdot$ Cultivation $\cdot$ Gulf of Mannar · Hollow cement block · Open sea · Seedling density

\section{INTRODUCTION}

Members of the order Gelidiales are among the economically important algae and account for $>33 \%$ of the total agarophytes (55650 tons dry wt) harvested annually worldwide (McHugh 2003). Although species of Gelidium and Pterocladia constitute the bulk of biomass in the global agar industry, Gelidiella is an important source of raw material in Pacific and Indian Ocean countries (Villanueva et al. 1999, Ganzon-Fortes 1997, Ganesan et al. 2008). In India, Gelidiella acerosa (Forsskål) G. Feldmann et Hamel is an important source of raw material for good quality agar and is harvested from natural stocks by domestic industries. The agar obtained from this alga has been reported to have gel strengths ranging from 450 to $845 \mathrm{~g} \mathrm{~cm}^{-2}$ for a $1.5 \%$ agar solution (w/v) at $20^{\circ} \mathrm{C}$ (Prasad et al. 2007). The annual harvest data for 2000 to 2003 showed an upward trend and ranged between 491and 665 tons dry wt (Kaliaperumal et al. 2004). Earlier studies conducted on exploited natural G. acerosa beds (Umamaheswara Rao 1973, Thomas et al.1975, 1978, Rama Rao \& Subbaramaiah 1977, Ganesan et al. 2008) have shown declining production rates when harvested successively. The continuous harvesting of natural stocks is a growing concern for the long-term sustainability of this resource. To mitigate the exploitation pressure on natural stocks, it is important to augment this valuable resource through sustainable cultivation practices. Successful cultivation depends on several factors including farm management practices, site selection, culture methodology, type of germplasm, nature of 
substratum, time of planting and season of cultivation (Pickering 2006).

Field cultivation experiments for Gelidiella acerosa began with propagation of vegetative fragments using long-line rope method (Subbaramaiah et al. 1975), bottom stone method (Patel et al. 1979) and single raft floating technique (SRFT) (Subbaramaiah \& Banumathi 1992). Spore-based methods of culturing this alga in the laboratory have also been attempted (Umamaheswara Rao 1974, Mairh et al. 1990). However, seasonality in spore shedding, low viability of spores and subsequent slow growth of propagules have limited the scope of success in developing sporebased propagation methods.

Despite several attempts, no successful cultivation methodology has been developed for this economically important alga. Consequently, natural stocks have been constantly exploited for agar in India. The growing demand for raw material together with overexploitation of natural stocks have led to investigations on the farming of this alga in the sea. In the present work, 4 different culture methods were evaluated to determine the feasibility of field cultivation based on biomass yield and daily growth rate (DGR). Further, the effects of seedling density, cultivation period and germplasm source were also investigated using the coral block method for successful field cultivation of Gelidiella acerosa in India. Development of cultivation techniques for seaweeds of high industrial utility will not only conserve biodiversity but also increase oceanic productivity while minimizing exploitation pressure on natural resources.

\section{MATERIALS AND METHODS}

Study site. Field cultivation of Gelidiella acerosa was carried out at Ervadi $\left(9^{\circ} 12.49^{\prime} \mathrm{N}, 78^{\circ} 43.59^{\prime} \mathrm{E}\right)$ in the Gulf of Mannar, India. The Ervadi coast has a large flat intertidal reef covered with extensive G. acerosa beds with intermittent Sargassum wightii Greville and Turbinaria conoides (J. Agardh) Kutzing beds. The substratum consists of coralline rocks with small patches of sand beds. The flat reef is always submerged in water, with the height of the water being $\sim 0.3$ and $\sim 1.0 \mathrm{~m}$ during the lowest low tide and highest high tide, respectively.

Field cultivation methods. Four different cultivation methods were evaluated for their yield potential based on biomass yield and DGR values for undertaking scaled-up cultivation of Gelidiella acerosa in the Gulf of Mannar region. These experiments were carried out during 2004 to 2006. A total of 4 harvests were made at $180 \mathrm{~d}$ intervals. In all methods, harvesting was done by cutting the well-grown portion of the plant and leaving the basal portion on the substratum as seedling material for further growth in the subsequent cultivation period.

Floating raft method: A square frame $(1.5 \times 1.5 \mathrm{~m})$ made of bamboo ( 7.5 to $10 \mathrm{~cm}$ diameter) was used for cultivation (Fig. 1A,B). Each raft contained 20 parallel polypropylene ropes (Garware wall ropes) of $3 \mathrm{~mm}$ diameter, which were fixed equidistantly for tying seedlings. Cuttings of $\sim 0.8 \mathrm{~g}$ fresh weight each were fastened to the polypropylene ropes at $5 \mathrm{~cm}$ intervals using nylon thread. Each rope had 25 propagules with a total fresh weight of $20 \mathrm{~g} \mathrm{rope}^{-1}$. A raft with $20 \mathrm{such}$ ropes had an initial seedling density of $400 \mathrm{~g}$ fresh wt raft $^{-1}$ or $178 \mathrm{~g}$ fresh wt. $\mathrm{m}^{-2}$. A total of $25 \mathrm{rafts}$ was used in this study; the rafts were tied and floated in 2 rows, with one row having 12 and the other having 13 rafts. Each row was held firmly in the sea (shallow subtidal waters) by using anchors (boulders) at both sides.

Bottom net method: A square net $(2 \times 2 \mathrm{~m})$ made up of a $3 \mathrm{~mm}$ polypropylene rope was used for this method. A total of 40 ropes of $2 \mathrm{~m}$ length each were woven vertically and horizontally so as to obtain a net with a mesh size of $10 \times 10 \mathrm{~cm}$ (Fig. 1C,D). Each $2 \mathrm{~m}$ long rope had a total of 20 cuttings $(\sim 0.5 \mathrm{~g}$ fresh wt. each) planted at $10 \mathrm{~cm}$ intervals with a total fresh weight of $10 \mathrm{~g} \mathrm{rope}^{-1}$. A net as described above had an initial seedling weight of $400 \mathrm{~g}$ fresh wt net ${ }^{-1}$ or $100 \mathrm{~g}$ fresh wt $\mathrm{m}^{-2}$. The seeded nets were tied at all 4 corners to vertical bamboo poles erected in the sea at $2 \mathrm{~m}$ depth. Stone sinkers were used to anchor the seeded nets at $25 \mathrm{~cm}$ above the bottom. A total of 10 nets were distributed in 2 rows with each row having 5 nets.

Coral block method: In the bottom coral block method, frond cuttings of Gelidiella acerosa were first tied on nylon twine (1.0 to $1.5 \mathrm{~mm}$ ) which was then wound around nails hammered into coral blocks (Fig. 1E,F)). A total of $25 \mathrm{~m}$ of seeded twine was used for each coral block with $1 \times 1 \mathrm{~m}$ surface area. The $25 \mathrm{~m}$ seeded twine had a total of 500 cuttings of $0.8 \mathrm{~g}$ fresh wt each, spaced at $\sim 5 \mathrm{~cm}$ intervals and having $400 \mathrm{~g}$ fresh wt $\mathrm{m}^{-2}$ as initial seedling density. The 25 seeded coral blocks were kept at the bottom in both the intertidal and subtidal regions ( 0.5 to $3.0 \mathrm{~m}$ depth). Harvesting was done at $180 \mathrm{~d}$ intervals and biomass yields were quantified.

Hollow cylinder cement block method: Hollow cylindrical cement blocks with a $0.5 \mathrm{~m}^{2}$ surface area were used for cultivation. Cuttings from fronds of Gelidiella acerosa were directly inserted between the lays of a $3 \mathrm{~mm}$ polypropylene rope and the rope wound around the block as shown in Fig. 1G,H. A total length of $15 \mathrm{~m}$ of seeded rope was used for one hollow circular cement block. Each seeded rope had a total of 300 cuttings of 0.6 to $0.7 \mathrm{~g}$ fresh wt each, spaced at $\sim 5 \mathrm{~cm}$ intervals and having $200 \mathrm{~g}$ fresh wt block ${ }^{-1}$ or $400 \mathrm{~g}$ 

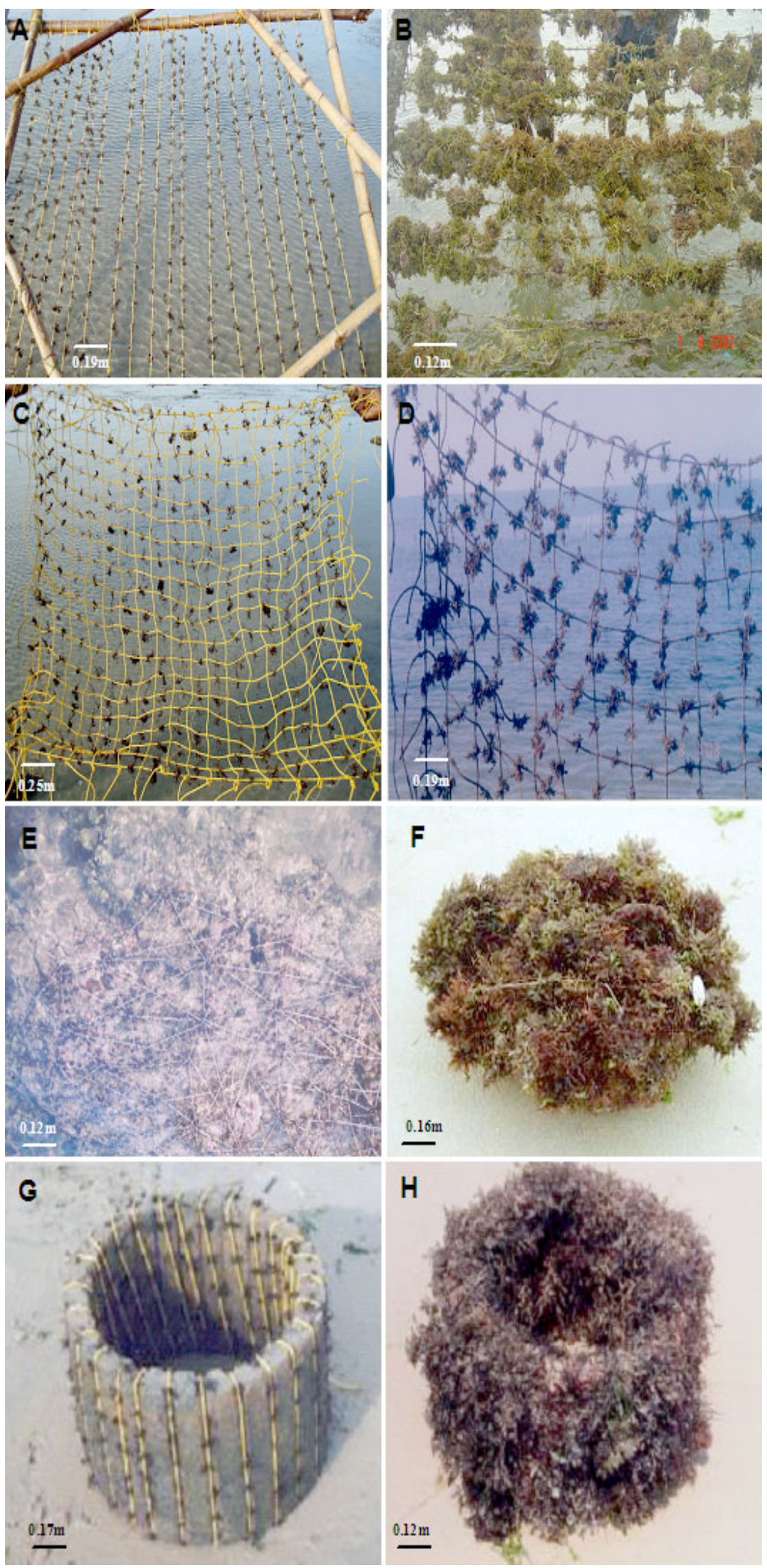

Fig. 1. Gelidiella acerosa. Different methods of cultivation: (A, B) raft, $(C, D)$ net, $(E, F)$ coral block, $(G, H)$ cement block; $(A, C, E$, G) with initial seedlings, $(B, D, F, H)$ with fully grown plants before harvesting 
fresh wt $\mathrm{m}^{-2}$ as the initial seedling material. The 100 seeded blocks were kept at the bottom of both the intertidal and subtidal regions ( 0.5 to $3.0 \mathrm{~m}$ depth), and placed at $0.5 \mathrm{~m}$ intervals to ensure free flow of water along all sides of the cement blocks. Harvesting of seaweeds was done at 180 d intervals and crop yields determined.

Evaluation parameters. The 4 cultivation methods were evaluated by measuring DGR (\%) and biomass yield as elaborated below.

Daily growth rate: DGR (\%) was calculated following the formula of Dawes et al. (1993) as follows:

$$
\operatorname{DGR}(\%)=\ln \left(W_{\mathrm{f}} / W_{0}\right) / t \times 100
$$

where $W_{\mathrm{f}}$ is the final fresh weight after $t$ days of culture, and $W_{0}$ is the initial fresh weight.

Determination of biomass: Biomass was determined after washing the plants thoroughly in seawater to remove all attached epiphytes and fauna. Excess water was drained off by keeping harvested plants on a mat for 10 to $15 \mathrm{~min}$ and fresh weights were then measured using an analytical balance.

Biomass $(Y)$ expressed as mean $g$ fresh wt $\mathrm{m}^{-2}$ was determined using the modified formula of Doty (1986) that included the initial weight of the seedlings as follows:

$$
Y=\left(W_{\mathrm{f}}-W_{\mathrm{i}}\right) / \mathrm{m}^{2}
$$

where $W_{\mathrm{f}}$ is the final fresh weight, $W_{\mathrm{i}}$ is the initial fresh weight, and $\mathrm{m}^{2}$ is the area covered.

Determination of optimum seedling density using the coral block method. This experiment was undertaken to determine the effect of initial seeding density on the biomass yield and DGR. Five densities: 200, 300, 400, 500 and $600 \mathrm{~g}$ fresh wt $\mathrm{m}^{-2}$ were studied using the coral block method. Seeding on coral blocks was done using the coral block method described earlier. The distance between 2 cuttings on the nylon twine was adjusted so as to achieve the desired seedling densities. Ten coral blocks of $1 \times 1 \mathrm{~m}$ surface area were used for studying each seedling density. Two harvests were made at 180 d intervals during 2001 to 2002. The regenerated material was harvested by pruning, leaving behind basal plant parts for further growth. Biomass and DGR were determined as described above.

Determination of optimum cultivation period using the coral block method. This study was undertaken in 2003 using the coral block method to optimize the cultivation period for obtaining maximum biomass of Gelidiella acerosa. Seeding and cultivation was done as described for the coral block method. The coral blocks seeded with $G$. acerosa were regularly harvested at 30,60,90,120, 150 and $180 \mathrm{~d}$ intervals and yields were determined by weighing the biomass from respective stones. A total of 10 coral blocks with $1 \times 1 \mathrm{~m}$ surface area was used for each cultivation period.

Selection of fast-growing wild germplasm for cultivation of Gelidiella acerosa. This experiment was conducted to select the fastest-growing germplasm of $G$. acerosa from wild populations. G. acerosa grown in different tidal regimes and habitats on the Gulf of Mannar coast viz. Pudumadam (intertidal rock), Ervadi (intertidal reef), Rameswaram (subtidal rock) and Sethukarai (subtidal reef) were collected and cultivated using the coral block method at Ervadi during 2001 to 2002 . Ten coral blocks with $1 \times 1 \mathrm{~m}$ surface area were seeded with germplasm collected from the different locations and cultivated for $180 \mathrm{~d}$ periods. Initial seedling density, cultivation and harvesting methods were as described for the coral block method. Biomass and DGR were determined as described earlier for 3 harvests with $180 \mathrm{~d}$ duration each.

Statistical analysis. ANOVA was performed to determine the significance of differences in: DGR and biomass yield for different culture techniques, different strains, and different initial seedling densities as well as biomass yield for different cultivation periods $(p=0.05)$. Tukey's HSD test was used to separate means whenever ANOVA showed significant $F$ values. Pearson's correlation analysis was used to determine the correlation of biomass and DGR with initial seedling density and cultivation period. Statistical analyses were performed using the software SYSTAT version 7 .

\section{RESULTS}

\section{Evaluation of cultivation methods}

Biomass and DGR values for the floating raft method increased exponentially from the 1st to the 3rd harvest (977 to $1288 \mathrm{~g}$ fresh wt $\mathrm{m}^{-2}$ and 1.11 to $1.31 \%$, respectively) and decreased sharply in the 4 th harvest (973 $\mathrm{g}$ fresh wt $\mathrm{m}^{-2}$ and $1.13 \%$ ). Biomass and DGR values for the coral block and cement block methods closely followed each other. The above 2 values were higher for coral blocks in the 1 st $(800 \pm 35 \mathrm{~g}$ fresh wt $\mathrm{m}^{-2}$ and $0.38 \pm 0.15 \%$, respectively) and the 3rd harvests $\left(738 \pm 40 \mathrm{~g}\right.$ fresh wt $\mathrm{m}^{-2}$ and $\left.0.34 \% \pm 0.6\right)$ while the same values were higher for cement blocks in the 2 nd $\left(600 \pm 30 \mathrm{~g}\right.$ fresh $\mathrm{wt} \mathrm{m}^{-2}$ and $\left.0.23 \pm 0.16 \%\right)$ and the 4 th harvests $\left(792 \pm 60 \mathrm{~g}\right.$ fresh wt $\mathrm{m}^{-2}$ and 0.38 $\pm 0.12 \%$ ). Biomass and DGR for the coral block and cement block methods differed significantly $(\mathrm{p}<0.05)$ in the $2 \mathrm{nd}, 3 \mathrm{rd}$ and 4 th harvests but not in the 1 st harvest $(p>0.05)$. Lowest biomass values were registered for the bottom net method of cultivation in the $1 \mathrm{st}, 2 \mathrm{nd}$ and 4 th harvests (227 to $350 \mathrm{~g}$ fresh wt $\mathrm{m}^{-2}$ ). This method had significantly lower $(\mathrm{p}<0.001)$ bio- 

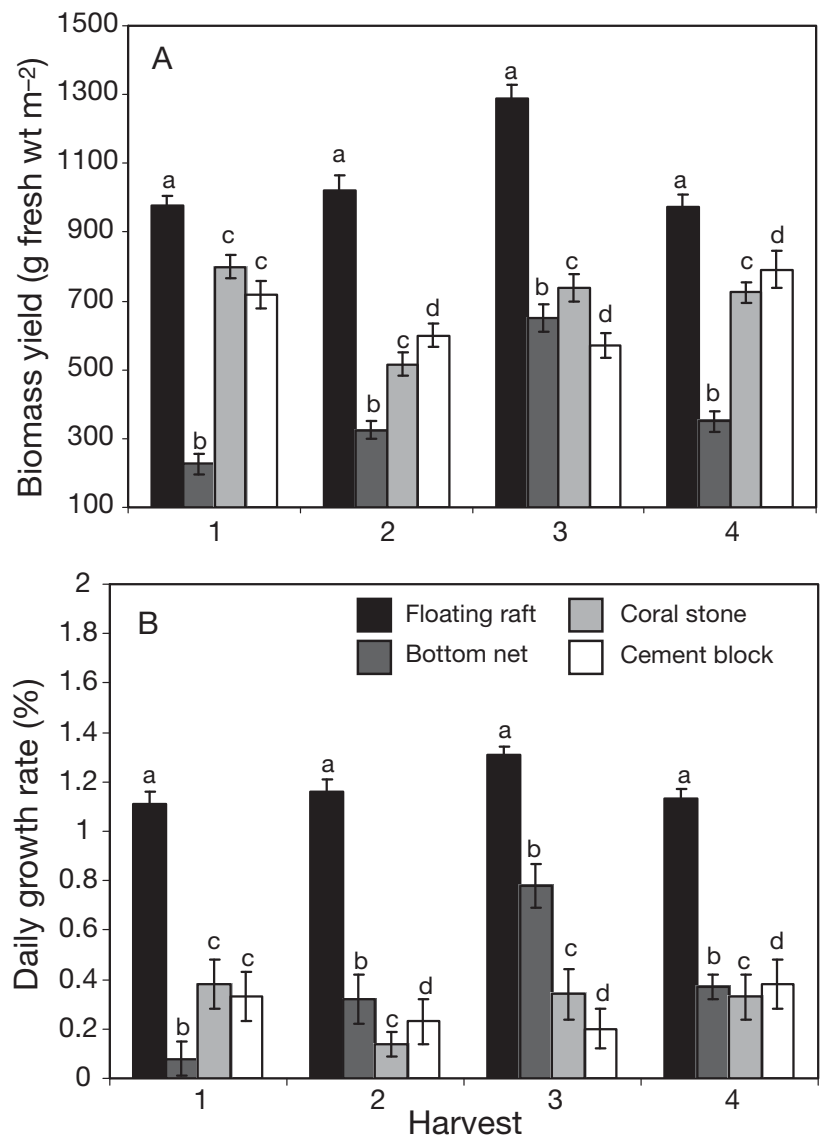

Fig. 2. Gelidiella acerosa. (a) Biomass and (b) daily growth rate under different cultivation methods. Error bars: \pm 2 SD. Different small letters over bars denote significant difference at $\mathrm{p}<0.05$

mass values than the other 3 methods of cultivation. Lowest DGR $(0.08 \pm 0.06 \%)$ were also registered for the bottom net method during the 1st harvest. The floating raft method showed consistently higher biomass and DGR values that were significantly higher $(p<0.001)$ than those in the other methods in all the 4 harvests studied (Fig. 2A,B).

\section{Optimum seedling density using the coral block method}

Biomass increased with increasing seedling density and the maximum biomass was obtained at an initial seedling density of $500 \mathrm{~g}$ fresh wt $\mathrm{m}^{-2}$ both in the 1st $\left(1425.0 \pm 90.0 \mathrm{~g}\right.$ fresh wt $\left.\mathrm{m}^{-2}\right)$ and $2 \mathrm{nd}(750.0 \pm 50.0 \mathrm{~g}$ fresh wt $\mathrm{m}^{-2}$ ) harvests (Fig. 3A). Biomass values at initial seedling densities of 400,500 and $600 \mathrm{~g}$ fresh wt $\mathrm{m}^{-2}$ were not significantly different from each other in both harvests but were significantly higher $(p<0.001)$ than those at the lowest initial densities (200 and $300 \mathrm{~g}$ fresh $\mathrm{wt} \mathrm{m}^{-2}$ ). Correlation analysis showed that the mean biomass yield was positively correlated $(\mathrm{r}=$ $0.958, \mathrm{p}<0.001$ ) with seedling density.

In contrast, DGR showed a reverse trend by registering the highest DGR values $(0.71 \pm 0.07$ and $0.48 \pm$ $0.06 \%$ ) at the lowest initial seedling density (200 g fresh wt $\mathrm{m}^{-2}$ ) in both the 1st and the 2nd harvests respectively (Fig.3B). DGR at the lowest initial seedling density differed significantly $(p<0.05)$ from values obtained at the higher densities (300 to $600 \mathrm{~g}$ fresh $\mathrm{wt} \mathrm{m}^{-2}$ ).

\section{Optimum cultivation period using the coral block method}

Cultivation period showed a considerable effect on the biomass of Gelidiella acerosa. Biomass values varied from a minimum of $86 \pm 12 \mathrm{~g}$ fresh $\mathrm{wt} \mathrm{m}^{-2}$ for $30 \mathrm{~d}$
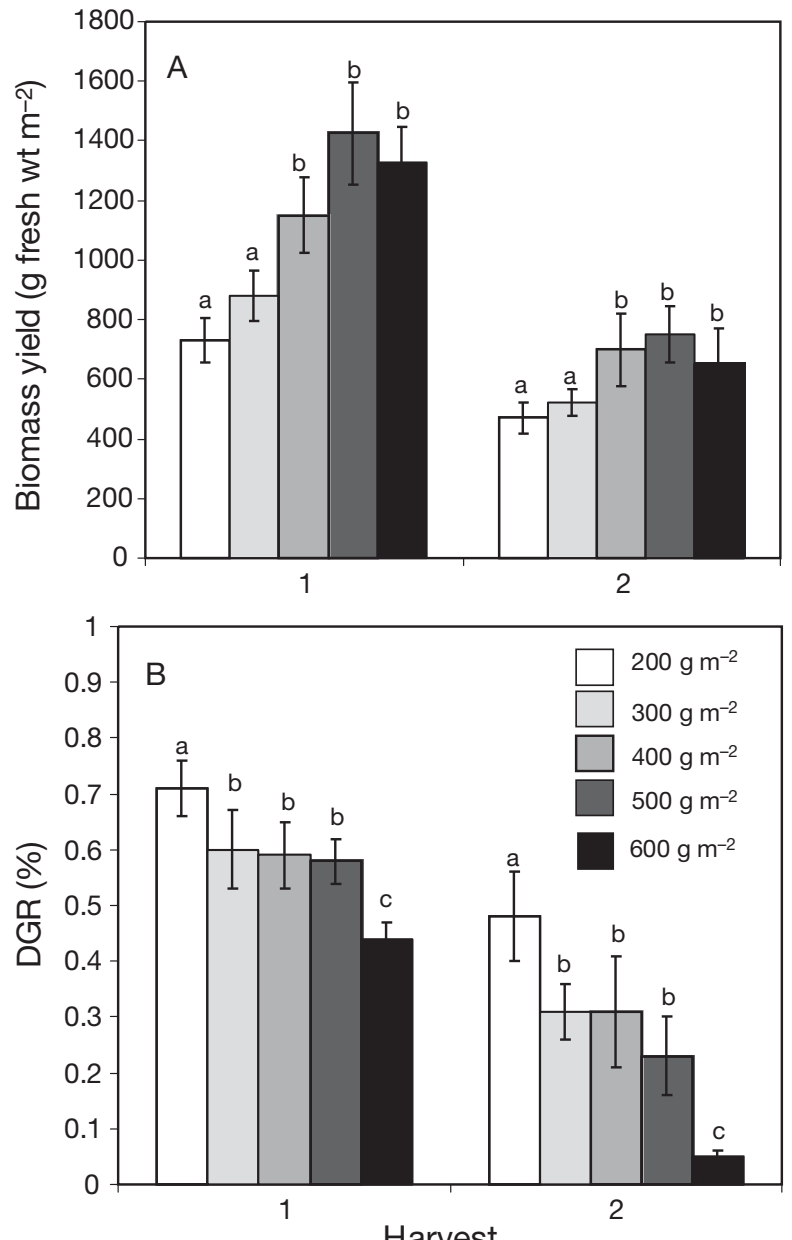

Fig. 3. Gelidiella acerosa. (a) Biomass and (b) daily growth rate obtained at different initial seedling densities using the coral block method. Error bars: \pm 2 SD. Different small letters over bars denote significant difference at $p<0.05$ 


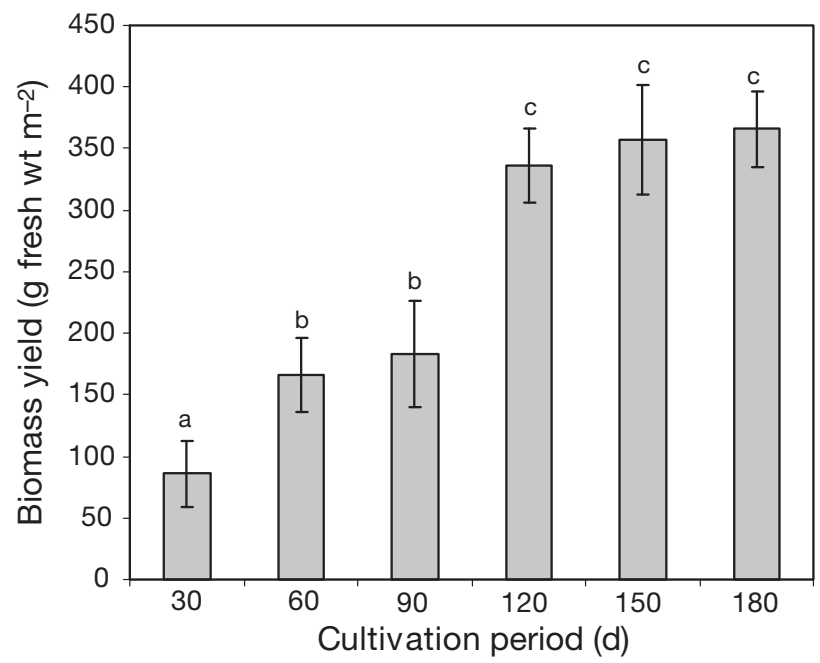

Fig. 4. Gelidiella acerosa. Biomass obtained for different cultivation periods using the coral block method. Error bars: \pm 2 SD. Different small letters over bars denote significant difference at $p<0.05$

of cultivation to a maximum of $367 \pm 45 \mathrm{~g}$ fresh wt $\mathrm{m}^{-2}$ for a $180 \mathrm{~d}$ cultivation period. Correlation analysis showed that biomass was positively correlated ( $\mathrm{r}=$ $0.919, \mathrm{p}<0.001$ ) with cultivation period. The maximum biomass obtained at a 180 d cultivation period was significantly different $(\mathrm{p}<0.001)$ from values obtained at 30, 60 and $90 \mathrm{~d}$ of cultivation (Fig. 4) but did not significantly differ $(p>0.05)$ from biomass values obtained at 120 and $150 \mathrm{~d}$ cultivation periods.

\section{Selection of fast-growing Gelidiella acerosa germplasm from wild stocks}

Gelidiella acerosa from Sethukarai (subtidal reef) showed the highest biomass $(367 \pm 24.1$ and $525 \pm$ $34.6 \mathrm{~g}$ fresh wt $\left.\mathrm{m}^{-2}\right)$ and DGR $(0.34 \pm 0.08$ and $0.54 \pm$ $0.04 \%$ ) during the 1 st and the 3rd harvests respectively (Fig. 5A,B). Biomass and DGR values at Sethukarai significantly differed $(p<0.001)$ from those in the remaining 3 places in the 1st harvest and from those in Pudumadam (intertidal rock) and Ervadi (intertidal reef) but not significantly from those in Rameswaram (subtidal rock) in the 3rd harvest. $G$. acerosa from Rameswaram (subtidal rock) showed marginally higher biomass yield $(400 \pm 28.0 \mathrm{~g}$ fresh wt $\left.\mathrm{m}^{-2}\right)$ and DGR $(0.39 \pm 0.04 \%)$ in the 2 nd harvest. Biomass yield and DGR values at Rameswaram (subtidal rock) significantly differed from those at Pudumadam (intertidal rock) $(\mathrm{p}<0.004)$ and Sethukarai (subtidal reef) $(p<0.005)$ but not from those at Ervadi (intertidal reef) $(\mathrm{p}>0.05)$.
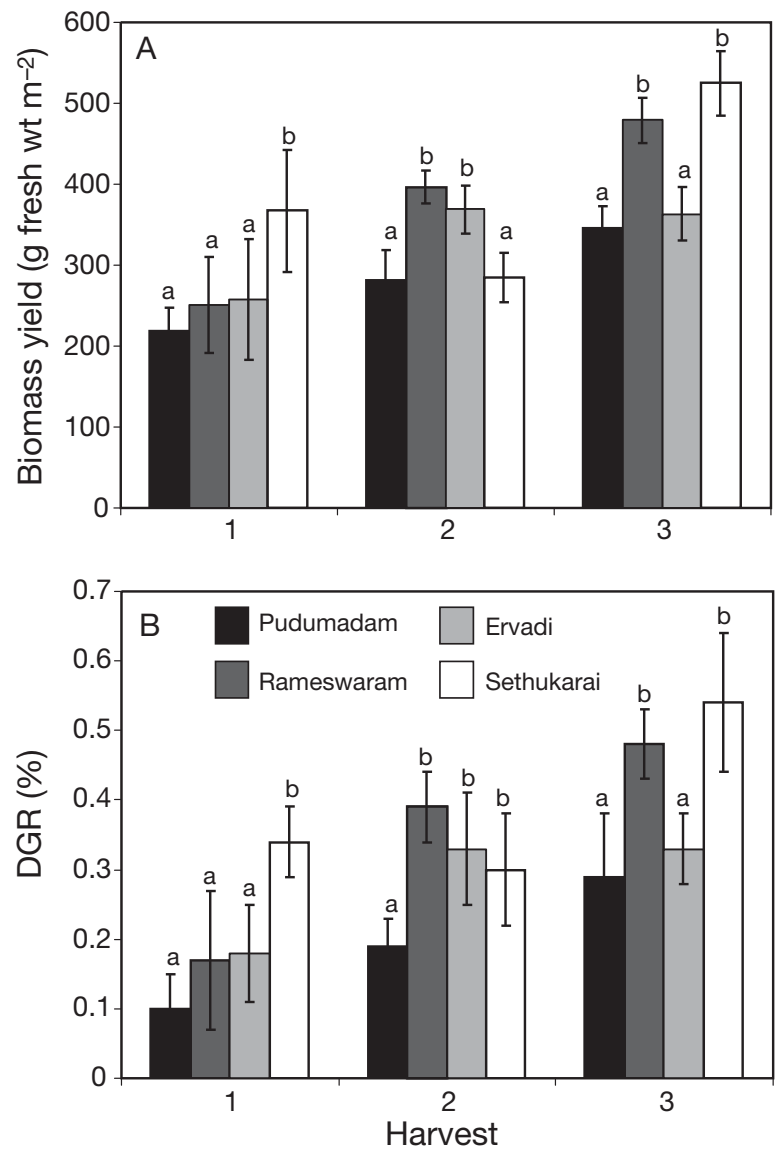

Fig. 5. Gelidiella acerosa. (a) Biomass and (b) daily growth rate obtained for different wild populations using the coral block method. Error bars: \pm 2 SD. Different small letters over bars denote significant difference at $\mathrm{p}<0.05$

\section{DISCUSSION}

Of the 4 culture methods, the floating raft method was found to give better biomass and DGR values. In the raft method, the plants are at the surface of the water column and get better exposure to sunlight besides experiencing stronger water currents. Other advantages of the raft method are that the rafts can be managed and relocated with ease if required for sustaining biomass production; it also allows a wider choice of farming sites, circumventing all site selection issues (e.g. water depth, nature of underwater terrain, etc.) encountered with other bottom culture methods. The raft method is being successfully employed for large-scale cultivation of Kappaphycus in India (Eswaran et al. 2002) and Eucheuma spp. in the Philippines (Trono 1990). The low yields observed in the bottom net method could be due to the low seedling densities used. Low seedling densities irrespective of culture method yielded lower biomass. Further, no 
spreading of the alga on the substratum was observed in the bottom net method and the biomass of individual plants was also lower compared with the other 3 methods. In cement blocks, although attachment and spreading of the alga on the substratum was found to be quite common, spreading was mainly confined to only the upper circumference of the cylinders, which accounts for 10 to $20 \%$ of the total surface area. Low water circulation, shading and poor light availability in the inner surface of the cement blocks might have affected algal growth. The outer surface was covered with epiphytes. Other algae like Caulerpa, Sargassum and Turbinaria also colonized the outer surface and competed with Gelidiella acerosa for space and possibly for nutrients. The floating raft is also susceptible to epiphytic algae but relatively less so than the other methods and could be removed with ease. The coral block method also suffered from similar problems as the cement block method; in addition the former cannot be advocated for large-scale cultivation due to ecological concerns.

The maximum DGR of $1.31 \%$ obtained for Gelidiella acerosa using the raft method in the present study is relatively much lower than values reported for other members of the order Gelidiales. Sousa-Pinto et al. $(1996,1999)$ reported DGR values of $21 \%$ for Gelidium robustum and $10 \%$ for $G$. pulchellum in short-term laboratory experiments. Likewise, DGR values of 13.2\% for Gelidium sp. (Titlyanov et al. 2006), 33.3\% for G. rex (Rojas et al.1996), 28.3\% for Pterocladia capillacea (Gal-Or \& Israel 2004), 6.5\% for G. crinale (Boulus et al. 2007) and $7 \%$ for G. sclerophyllum (Rodriguez 1996) have been reported for cultures grown in either laboratory or outdoor tanks. In contrast, a DGR of $1 \%$ has been reported for G. robustum grown in open-sea conditions (Pacheco-Ruiz \& Zertuche-Gonzalez 1995). Cultivation in the open sea suffers from problems of fouling due to epibionts that severely retard growth and decrease DGR, which has become a major concern for slow-growing species (Rojas et al. 1996). Repeated epiphyte infestation of $G$. sesquipedale in open-sea cultivation has caused withdrawal of the cultured alga from cultivation sites in Spain (Seoane-Camba 1997). Conversely, short-term experiments in laboratory or outdoor culture allow better control over experimental conditions and help circumvent the above mentioned problems leading to higher growth rates. The DGR values of Gelidiella acerosa obtained for the raft method in the present study $(1.31 \%)$ are somewhat closer to those reported for rope culture (Subbaramaiah \& Banumathi 1992) and for the coral stone method (Patel et al. 1979) in open-sea conditions.

The experiments carried out to optimize seedling density based on DGR and biomass values showed divergent results. DGR was always higher at lower initial seedling densities (200 $\mathrm{g}$ fresh $\mathrm{wt} \mathrm{m}^{-2}$ ) while biomass was higher at higher initial seedling densities (500 $\mathrm{g}$ fresh wt $\mathrm{m}^{-2}$ and above). The lowest biomass values despite the highest DGR values observed at lower initial seedling density could be mainly due to the lower initial seedlings per unit of surface area of cultivation substratum. Substrata with lower seedling densities often had settlement of epiphytes such as Jania, Lyngbya, Ulva, Hypnea and Acanthophora. The epiphytic species could have directly competed with Gelidiella acerosa for space and nutrients, resulting in lower turnover production. Similar findings have also been reported for Hypnea musciformis (Wulfen) J. V. (Ganesan et al. 2006) and Kappaphycus alvarezii (Doty) Doty ex. P. Silva (Hurtado et al. 2001) in opensea cultivation. The greater the density of seedlings per unit of cultivation area, the higher is the biomass and the lower are the DGR values, and in turn the lesser is the number of epiphytes. Therefore, an initial seedling density of $500 \mathrm{~g}$ fresh wt $\mathrm{m}^{-2}$ is recommended as ideal for scaled-up cultivation.

Considerable success has been achieved in clonal propagation and selection of seaweed strains with superior traits (Santelices 1992, Reddy et al. 2008). Cultivation of such seaweed strains not only provides predictable yields of high quality material but also makes cultivation economically attractive. Continued overexploitation of natural stocks of Gelidiella acerosa could deplete their genetic diversity and undermine the benefits of genetic improvement of the species and the prospects of cultivation in the long run (Kaliaperumal 1998).The subtidal germplasm from Sethukarai and Rameswaram that are not accessible for commercial harvests recorded higher biomass yield and DGR than the other populations investigated in this study.

Yields were maximized at a 180 d cultivation period. Extended cultivation beyond $180 \mathrm{~d}$ adversely affected the growth rate of plants due to senescence, epiphyte infestation and biofouling (Subbaramaiah et al. 1975). Recent work on Gelidiella carried out at Ervadi revealed the settlement of the sponge Sigmadocia pumila LendenFeld over Gelidiella acerosa cultivated for $>180 \mathrm{~d}$ that resulted in stunted growth and bleaching of G. acerosa leading to poor crop yields (Sahu et al. 2007).

For Gelidiella, April to September is the best growing season in the Gulf of Mannar. April is the ideal month for seeding and transplantation of propagules in the sea. Two harvests can be made in a year, i.e. one in August-September and the other in March-April. During January to March, basal portions of the thallus persisted but showed little growth. The observed peak growth seasons of Gelidiella acerosa in cultivation coincide well with the findings of Umamaheswara Rao 
(1973) of peak growth during July to August and April in the Gulf of Mannar coast. Highest growth during the southwest monsoon period (June to September) may be partly due to strong water currents and tidal flushing. It has been suggested that water currents enhance the growth rates of seaweeds by reducing the thickness of the diffusion boundary layer around the algal surface (Wheeler 1988). The decreased thickness of the boundary layer thus increases the supply of inorganic carbon, phosphate, nitrate and other micronutrients to the thallus (Wheeler 1988, Hurd 2000), and facilitates the removal of algal metabolic products such as $\mathrm{O}_{2}$ and $\mathrm{OH}^{-}$ions (Gonen et al. 1995), excess hydrogen peroxide and halogenated organic compounds (Mtolera 1996) away from the plant surface.

The overall findings of this study indicate that the raft method of cultivation of Gelidiella acerosa is more advantageous with respect to yield and farm maintenance than the other 3 methods studied. Further, cultivation of seedlings collected from Sethukarai at an initial seedling density of $\geq 500 \mathrm{~g}$ fresh wt $\mathrm{m}^{-2}$ for a period of $180 \mathrm{~d}$ could be other important criteria for feasible cultivation of this alga in open-sea conditions. Periodic cleaning and weeding of competitive species from the cultivation substratum is of paramount importance for successful cultivation in the open sea.

The indiscriminate harvesting of Gelidiella acerosa from wild stocks throughout the year has caused the dwindling of this resource that affected the productivity and landscape of the intertidal ecosystem. The propagation of industrially utilized seaweeds which are otherwise harvested from wild stocks may help conserve and maintain wild beds along with associated biota.

Acknowledgements. We thank P. K. Ghosh, Director of CSMCRI, Bhavnagar for his inspiring ideas, suggestions and support. Funding was provided by the Department of Biotechnology (BT/PR 1721/AAQ/03/89/99) and the Council of Scientific and Industrial Research (NWP-018), New Delhi, India.

\section{LITERATURE CITED}

Boulus A, Spaneir E, Friedlander M (2007) Effect of outdoor conditions on growth rate and chemical composition of Gelidium crinale in culture. J Appl Phycol 19:471-478

Dawes CJ, Lluisma AD, Trono CG (1993) Clonal propagation of Eucheuma denticulatum and Kappaphycus alvarezii for Philippine seaweed farms. Hydrobiologia 260/261: 379-383

Doty MS (1986) Estimating returns from producing Gracilaria and Eucheuma on line farms. Monogr Biol 4:45-62

Eswaran K, Ghosh PK, Mairh OP (2002) Experimental field cultivation of Kappaphycus alvarezii (Doty) Doty. ex. P. Silva at Mandapam region. Seaweed Res Util 24:67-72

Gal-Or S, Israel A (2004) Growth responses of Pterocladiella capillacea (Rhodophyta) in laboratory and outdoor cultivation. J Appl Phycol 16:195-202
Ganesan M, Thiruppathai S, Jha B (2006) Mariculture of Hypnea musciformis (Wulfen) Lamouroux in south east coast of India. Aquaculture 256:201-211

Canesan M, Reddy CRK, Eswaran K, Jha B (2008) Seasonal variation in the biomass, quantity and quality of agar from Gelidiella acerosa from the Gulf of Mannar Marine Biosphere Reserve. Phycol Res 56:93-104

Ganzon-Fortes ET (1997) Influence of tidal location on morphology, photosynthesis and pigments of the agarophyte Gelidiella acerosa from northern Philippines. J Appl Phycol 9:525-532

- Gonen Y, Kimmel E, Friedlander M (1995) Diffusion boundary layer transport in Gracilaria conferta (Rhodophyta). J Phycol 31:768-773

Hurd CL (2000) Water motion, marine macroalgal physiology, and production. J Phycol 36:453-472

Hurtado AQ, Agbayani RF, Sanares R, Teresa M, Castro Mallare R (2001) The seasonality and economic feasibility of cultivating Kappaphycus alvarezii in Panagatan Cays, Caluya, Antique, Philippines. Aquaculture 199:295-310

Kaliaperumal N (1998) Seaweed resources and biodiversity values. In: Rajeswari Anand M, Dorairaj K, Parida A (eds) Proc Workshop on Biodiversity of the Gulf of Mannar Marine Biosphere Reserve, 27-28 Feb 1998, Chennai, p 92-101

Kaliaperumal N, Kalimuthu S, Ramalingam JR (2004) Present scenario of seaweed exploitation and industry in India. Seaweed Res Util 26:47-53

Mairh OP, Ramavat BK, Sreenivasa Rao P (1990) Nutrition, growth and tetraspore induction of Gelidiella acerosa (Forssk.) Feld. et Hamel (Gelidiellaceae, Rhodophyta) in culture. Bot Mar 33:133-141

McHugh DJ (2003) A guide to the seaweed industry. FAO Fisheries Technical Paper No. 441, FAO Publication, Rome, p 105

Mtolera MSP (1996) Photosynthesis, growth and lightinduced stress responses in the red alga Eucheuma denticulatum. PhD Thesis, Uppsala University

Pacheco-Ruiz I, Zertuche-Gonzalez JA (1995) Effect of water movement on the growth of Gelidium robustum (Gardn.) Hollenb. and Abb. (Rhodophyta). Cienc Mar 21:59-70

Patel JB, Gopal BV, Nagulan VR, Subbaramaiah K, Thomas PC (1979) Experimental field cultivation of Gelidiella acerosa at Ervadi in India. Proc Int Symp Marine Algae of the Indian Ocean region. CSMCRI, Bhavnagar, India, p 24-25

> Pickering T (2006) Advances in seaweed aquaculture among Pacific Island countries. J Appl Phycol 18:227-234

> Prasad K, Siddhanta AK, Ganesan M, Ramavat BK, Jha B, Ghosh PK (2007) Agars of Gelidiella acerosa of the west and southeast coasts of India. Bioresour Technol 98: 1907-1915

Rama Rao K, Subbaramaiah K (1977) Regeneration and regrowth of Gelidiella acerosa (Forssk.) Feldmann et Hamel at Kilakkarai southeastern shores of India. Indian J Mar Sci 6:175-177

Reddy CRK, Jha B, Fujita Y, Ohno M (2008) Seaweed micropropagation techniques and their potentials: an overview. J Appl Phycol 20:607-617

Rodriguez D (1996) Vegetative propagation by fragmentation of Gelidium sclerophyllum (Gelidiales, Rhodophyta). Hydrobiologia 326-327:361-365

Rojas R, Leon NM, Rojas RD (1996) Practical and descriptive techniques for Gelidium rex (Gelidiales, Rhodophyta) culture. Hydrobiologia 326-327:367-370

Sahu N, Ganesan M, Eswaran K (2007) Interference of Sigmadocia pumila, a poriferan, on the growth of red sea- 
weeds Gelidiella acerosa and Kappaphycus alvarezii. Curr Sci 92:1683-1685

Santelices B (1992) Strain selection of clonal seaweeds. In: Round FE, Chapman DJ (eds) Prog Phycol Res 8: $86-115$

Seoane-Camba JA (1997) Gelidium sesquipedale cultivation in Galicia (Spain). Lagascalia 19:179-186

Sousa-Pinto I, Lewis R, Polne-Fuller M (1996) The effect of phosphate concentration on growth and agar content of Gelidium robustum (Gelidiacea, Rhodophyta) in culture. Hydrobiologia 326-327:437-443

Sousa-Pinto I, Murano E, Coelho S, Felga A, Pereira R (1999) The effect of light on growth and agar content of Gelidium pulchellum (Gelidiaceae, Rhodophyta) in culture. Hydrobiologia 398-399:329-338

Subbaramaiah K, Banumathi R (1992) A preliminary note on the raft cultivation of Gelidiella acerosa. Phykos 31:1-5

Subbaramaiah K, Rama Rao K, Thomas PC, Nair MRP, Gopal BV, Nagulan VR (1975) Cultivation of Gelidiella acerosa. Salt Res India 11:33-36

Thomas PC, Rama Rao K, Subbaramaiah K (1975) Changes in the natural growth and agar content of Gelidiella acerosa (Forssk.) Feldmann et Hamel in an exploited population. Bot Mar 18:241-243

Editorial responsibility: Jana Davis, Annapolis, Maryland, USA
Thomas PC, Subbaramaiah K, Iyengar ERR (1978) Natural growth and agar content of Gelidiella acerosa (Forsskål) Feld. et Hamel in an exploited population. Rev Algol 13: 341-347

Titlyanov EA, Titlyanova TV, Kadel P, Lüning K (2006) Obtaining plantlets from the apical meristem of the red alga Gelidium sp. J Appl Phycol 18:167-174

Trono GC (1990) A review of the production technologies of tropical species of economic seaweeds. Reg Workshop on the Culture and Utilization of seaweeds. UNDP/FAO and NACA, Aug 27-Sept 1, 1990, Cebu City, p 1-28

Umamaheswara Rao M (1973) Growth and reproduction of Gelidiella acerosa in the Palk Bay and Gulf of Mannar near Mandapam. Indian J Fish 20:411-416

Umamaheswara Rao M (1974) Observations on fruiting cycle, spore output and germination of tetraspores in Gelidiella acerosa in the Gulf of Mannar. Bot Mar 17:204-207

- Villanueva RD, Montano NE, Romero JB, Aliganga A, Enriquez EP (1999) Seasonal variations in the yield, gelling properties, and chemical composition of agars from Gracilaria eucheumoides and Gelidiella acerosa (Rhodophyta) from the Philippines. Bot Mar 42:175-182

Wheeler WN (1988) Algal productivity and hydrodynamics: a synthesis. Prog Phycol Res 6:23-58

Submitted: May 7, 2008; Accepted: December 12, 2008 Proofs received from author(s): April 9, 2009 